\title{
Forgotten Intrauterine Contraceptive Device: A Rare Cause of Infertility
}

\author{
*Swende T Z MBBS, AFMCOG, MWACS**Ocheke A MBBS, AFMCOG, FWACS ${ }^{\star * *}$ Mohammed H MBBS, \\ AFMCS
}

*Department of Obstetrics and Gynaecology, Federal Medical Centre Makurdi, Nigeria, **Department of Obstetrics and Gynaecology and ${ }^{* * *}$ Department of Radiology, Jos University Teaching Hospital, Jos, Nigeria

\begin{abstract}
Worldwide, Intra Uterine Devices (IUDs) are among the most commonly used reversible methods of contraception 1. This is particularly true in developing countries. Insertion of IUD may be interval or postpartum. The concept of early postpartum IUD insertion has been investigated since the 1960s and has become accepted worldwide ${ }^{3}$, even though IUDs inserted in the immediate postpartum appear to have a higher expulsion rate ${ }^{4}$. Several complications associated with IUD use have been documented ${ }^{2}$, for instance, the association between IUD use and pelvic inflammatory disease or salpingitis has been demonstrated in several studies ${ }^{1}$. Contamination at the time of insertion has been suggested to be responsible forthis risk of infection".

We report here an unusual case of early postpartum IUD insertion without the patient's knowledge or adequate counselling sixteen years prior to presentation with secondary infertility.
\end{abstract}

Key Words: IUD, Infertility, Hysterosalpingogram.

Date Accepted for publication: 18th July 2007

Nig J Med 2009; 420 - 421

Copyright $\odot 2009$ Nigerian Journal of Medicine

\section{Case Report}

Mrs. M.C. a 32 year old para $1+0$ was referred from a peripheral clinic to do a hysterosalpingogram at the Radiology Department of the Jos University Teaching Hospital. She had a fourteen year history of inability to conceive despite adequate coitus. Her only pregnancy was out of wedlock, sixteen years prior to presentation. Delivery was at a General Hospital where she had received antenatal care. She recalled having a pelvic examination some hours after delivery by a 'physician' and being told of the need not to get pregnant until she was married. She had no other pelvic examination prior to presentation. She was illiterate and the first of two wives of her husband. They had been married for fourteen years. Her husband had four children with his second wife over the preceding eight years, hence his reluctance to seek medical assistance with the first wife. Review of systems was not contributory. On examination, she was young and healthy looking and there was no systemic abnormality.

The control film revealed an IUD projected in the pelvis in the region of the uterus. The Cu T 380A IUD was removed by gently pulling on the strings per vaginam using a pair of long artery forceps. Following the introduction of contrast via a Leech Wilkinson canular, the cervical canal and uterine cavity were outlined. The fallopian tubes were not outlined neither was there spillage of contrast into the peritoneal cavity. A clinical assessment of secondary infertility due to forgotten IUD and bilateral cornual blockage was made.

\section{Discussion}

The postpartum period is a time of tremendous emotional, social and physical change for most women ${ }^{4}$. Additionally, this patient was a single teenage mother with no formal education at the time of supposed insertion of the $\mathrm{Cu}$ T 380 device. These factors might have made it difficult for her to fully comprehend the trend of events. In this patient, the IUD was inserted in the immediate postpartum and remained insitu for 16 years, suggesting that the rate of expulsion after postpartum insertion may be governed more by the insertion technique rather than by the timing of insertion ${ }^{3}$.

The Cu T $380 \mathrm{~A}$ is probably the most effective currently available IUD with a failure rate of less than $1 \%$ per year 1. This factor alone, may sufficiently explain this patient's inability to conceive over a 14 year period. The additional finding of bilateral cornual blockage may have followed associated pelvic inflammatory disease (PID) or salpingitis with IUD use, even though studies have shown that the risk of PID is increased within the first 3-4 months following insertion, after which the risk is the same as in the normal population ${ }^{1}$.

The importance of adequate counselling cannot be over emphasized with matters related to contraception and reproductive health in general. With adequate 
counselling, the factor of illiteracy not withstanding, this patient would have been aware of the IUD she was carrying thus averting the sequelae seen in her case. Reproductive health care providers in developing countries must pay particular attention to detailed counselling of patients to avoid such cases in future. Moreover, complications such as this, though rare, may worsen the already low contraceptive prevalence in most of the developing world.

In conclusion, girl child education, female empowerment and counselling of clients on contraception and other reproductive health services are essential for effective reproductive health care.

\section{References}

1. Al Inany H. Current state of intrauterine contraceptive devices. Middle East Fertility Society Journal. 2007; 12: 8-12

2. Ikechebelu J.I. Onwusulu D.N. Displaced intrauterine contraceptive device causing severe menorrhagia. Trop J Obstet Gynaecol 2006; 23: 7071

3. Celen S. Moroy P. Sucak A. Aktulay A. Danisman N. Clinical outcomes of early postplacental insertion of intrauterine contraceptive devices. Contraception 2004; 69: 279-282

4. Shaw E. Kaczorowski J. Postpartum care What's new? Current Opin Obstet Gynecol 2007; 19:561-567 